\title{
Alternatives to the Use of Fetal Bovine Serum: Human Platelet Lysates as a Serum Substitute in Cell Culture Media
}

Caroline Rauch ${ }^{1}$, Elisabeth Feifel ${ }^{1}$, Eva-Maria Amann ${ }^{2}$, Hans Peter Spötl ${ }^{2}$, Harald Schennach $^{2}$, Walter Pfaller ${ }^{1}$, and Gerhard Gstraunthaler ${ }^{1}$

${ }^{1}$ Division of Physiology, Innsbruck Medical University, Innsbruck, Austria; ${ }^{2}$ Central Institute of Blood Transfusion and Immunology, University Hospital, Innsbruck, Austria

\begin{abstract}
Summary
The search for alternatives to the use of fetal bovine serum (FBS) in cell and tissue culture media has become a major goal in terms of the $3 R$ principles in order to reduce or to avoid harvesting of FBS from bovine fetuses, and, in terms of Good Manufacturing Practice (GMP), to ensure safe and animal product-free conditions for biomedical tissue engineering and (adult) stem cell therapy, respectively. In the present study, we investigated the feasibility of using platelet lysates $(P L)$ as a substitute for FBS, based on the fact that most of the potent mitogenic factors present in serum are derived from activated thrombocytes.

Platelet lysates were obtained from outdated human donor platelet concentrates. Methods were established to activate human donor platelets in order to achieve a maximum yield of platelet $\alpha$-granule growth factors. Platelet lysates were successfully introduced to grow and maintain anchorage-dependent and-independent human and animal cell lines. For cell culture experiments, cells were either grown in culture media supplemented with $10 \%$ FBS, 5\% PL, or under serum-free conditions. Growth experiments, viability assays, and platelet lysate-induced activation of ERK1/2 mitogen-activated protein kinase revealed platelet lysates as a valuable alternative to FBS in cell culture media.
\end{abstract}

Keywords: cell culture media, fetal bovine serum, serum-free cell culture, platelet lysates, non-animal alternatives

\section{Introduction}

Propagation of human and animal cells in vitro requires adequate culture conditions and culture media. The culture medium has to supply all essential nutrients for cell metabolism, growth and proliferation. Basal media are frequently supplemented with animal serum, mostly fetal bovine serum (FBS), which promotes cell growth and proliferation (Gstraunthaler, 2003; Lindl und Gstraunthaler, 2008). Animal serum is an extremely complex mixture of a large number of constituents, including low and high molecular weight biomolecules with different physiologically balanced growth-promoting and growth-inhibiting activities. The major functions of serum in culture media are to provide hormonal factors stimulating cell growth and proliferation, to promote differentiated functions, and to provide transport proteins, minerals, trace elements, lipids, attachment and spreading factors, and stabilizing and detoxifying factors needed for maintaining $\mathrm{pH}$ or to inhibit proteases either directly, such as $\alpha$-antitrypsin, or indirectly, by acting as an unspecific sink for proteases and other (toxic) molecules. FBS is superior to serum from adult animals because of its low gamma-globulin content, as a high content of antibodies may inhibit growth and proliferation.

Recently, major concerns were raised about the welfare of donor fetuses during harvesting of fetal blood (Brunner et al., 2010; van der Valk et al., 2004, 2010). Bovine fetuses from which blood is drawn for FBS production are obtained from pregnant cows sent to slaughter. When a pregnant cow is discovered at the slaughterline, the fetus is separated at the abattoir, and fetal blood is collected under aseptic conditions by puncturing the beating heart of the unanesthetized fetus using large diameter needles. Thus, fetal blood collection involves significant manipulation of the fetus (Jochems et al., 2002).

The use of in vitro human cell culture for tissue engineering, (adult) stem cell technology, and cell-based therapy has gained in importance during the last decade (Leist et al., 2008; Park and Eve, 2009; Taupin, 2007). Because of the undefined composition of FBS, the risk of contaminations, animal welfare concerns regarding its harvest and production, along with the problems of limited availability and the cost factor, the

Received July 6, 2011; accepted in revised form October 18, 2011. 
switch to serum-free alternatives is promoted by regulatory authorities, industry, and the research community in general (Falkner et al., 2006; Brunner et al., 2010; van der Valk et al., 2010). Examples for the limited usage of FBS are the field of multipotent mesenchymal stromal cells (MSCs) (Lange et al., 2007) and human embryonic stem cells (hESC). Concerns were raised that the incorporation of the nonhuman $\mathrm{N}$-glycolylneuraminic acid (Neu5Gc), present in animal serum, excludes FBS from application in human ES for cellular therapy (Martin et al., 2005; Taupin, 2006).

Other laboratories have already suggested that platelet lysates are a valuable, non-xenogenic alternative to FBS in cell culture (Bernardo et al., 2007; Doucet et al., 2005; Johansson et al., 2003). Physiologically, activated platelets are known to deliver a broad spectrum of growth factors and other active molecules by exocytosis at the site of injury. The growth factors released from $\alpha$-granules include platelet-derived growth factor (PDGF), epithelial growth factor (EGF), vascular endothelial growth factor (VEGF), basic fibroblast growth factor (bFGF), hepatocyte growth factor (HGF), and transforming growth factor $\beta 1$ (TGF- $\beta 1$ ) (King and Reed, 2002; Maguire and Fitzgerald, 2003; Reed et al., 2000; Rendu and Brohard-Bohn, 2001).

However, almost all lysates used so far contained high volumes of donor serum, i.e. potential allograft material (Abrams, 2005; Bieback et al., 2009; Spreafico et al., 2009). In the present study it was investigated whether separation of platelets from donor serum by washing in saline before their in vitro processing would provide lysates that promote cell growth and can be used as an alternative to FBS. As cell culture models continuous human and animal cell lines, grown as monolayers or in suspension, were used (Gstraunthaler, 1988).

\section{Materials and methods}

\section{Preparation of human platelet lysates}

Outdated human donor platelets obtained by different apheresis methods (Amicus ${ }^{\mathrm{TM}}$, Fenwal, Lake Zurich, IL, USA; Tri$\mathrm{ma}^{\mathrm{TM}}$, CaridianBCT, Lakewood, CO, USA) were provided by the blood bank of the Innsbruck Medical University Hospital. Platelet donor bags (one bag per donor) were each processed separately. Platelet concentrates, containing at least $2 \times 10^{11}$ donor platelets, were transferred under sterile conditions into 250 $\mathrm{ml}$ centrifugation cups and centrifuged at $6,000 \mathrm{x}$ g for $20 \mathrm{~min}$ in order to remove platelet additive solution (PAS) (Shanwell et al., 2003). The supernatant was aspirated and the platelets were washed with $0.9 \% \mathrm{NaCl}$. Platelets were resuspended in $15 \mathrm{ml}$ $0.9 \% \mathrm{NaCl}$ with a final cell count of $\sim 1.5 \times 10^{10}$ platelets $/ \mathrm{ml}$. The suspension was stored at $-20^{\circ} \mathrm{C}$ before lysate preparation by three freeze/thawing cycles. Aliquots of the platelet lysate were again stored at $-20^{\circ} \mathrm{C}$ for use within 4 weeks. Before addition to serum-free culture media, aliquots were thawed and spun at $8,000 \mathrm{x}$ for $10 \mathrm{~min}$ and supernatants were taken.

To identify the most efficient platelet activation method in order to achieve a maximum yield of growth factors, different physiological/biochemical or mechanical methods of in vitro platelet activation were tested (Burnouf et al., 2008; Ga- chet, 2000; Kamath et al., 2001; Reed et al., 2000; Rendu and Brohard-Bohn, 2001). Of the methods tested (coagulation with $\mathrm{CaCl}_{2}$, activation with ADP, fibrillar collagen type I, thrombin, thrombin receptor activating peptide, or zeolite), freeze-thawing of platelet suspension turned out to be the most effective procedure (Barano and Hammond, 1985). The method induces platelet disruption by hypo-osmotic shock and three repeated freezing/thawing cycles at $-20^{\circ} \mathrm{C}$.

\section{Counting of platelets}

Determination of platelet counts was performed by using the CASY ${ }^{\circledR}$ Technology Model TT (innovatis AG, Bielefeld, Germany). Platelets were diluted in $0.9 \% \mathrm{NaCl}$ for measurement with a $60 \mu \mathrm{m}$ diameter measuring capillary.

\section{Cell culture}

For tissue culture experiments mainly renal epithelial cells, particularly immortal LLC-PK 1 , LLC-PK 1 -FBPase ${ }^{+}$, MDCK, OK, and HK-2 cells were used (Gstraunthaler, 1988). Furthermore, the human leukemia cell lines Raji and THP-1 were used as models for suspension cultures. Cultures were incubated at $37^{\circ} \mathrm{C}$ with $5 \% \mathrm{CO}_{2}$. Routinely, cultures were fed three times a week. Confluent monolayers were subcultured with $0.25 \%$ trypsin and $0.02 \%$ EDTA in $\mathrm{Ca}^{2+}$ - and $\mathrm{Mg}^{2+}$-free buffered saline. Experimental cultures were grown in $10 \mathrm{~cm}$ plastic tissue culture dishes until confluent monolayers were achieved using $7 \mathrm{ml}$ culture medium.

Cell culture media were prepared from DMEM (Dulbecco's Modified Eagle's Medium) base (Cat. No. D-5030, SigmaAldrich, Vienna, Austria) supplemented with $5.5 \mathrm{mM}$ D-glucose, $2 \mathrm{mM}$ L-glutamine, $26.2 \mathrm{mM} \mathrm{NaHCO} 3$ and $17.8 \mathrm{mM}$ $\mathrm{NaCl}$ to correct for medium osmolarity (Gstraunthaler et al., 2000), 10\% FBS (Biochrom, Berlin, Germany), 1 mM sodium pyruvate, $0.011 \mathrm{~g} / \mathrm{l}$ phenol red and $100 \mathrm{U} / \mathrm{ml}$ penicillin and $100 \mu \mathrm{g} / \mathrm{ml}$ streptomycin. Suspension cultures were grown in RPMI-1640 medium supplemented with 10\% FBS and antibiotics. For culturing cells with platelet lysates, FBS was replaced by $5 \%$ PL. Serum-free cultures were without addition of either FBS or PL. All media additives were of tissue culture grade and were obtained from Sigma-Aldrich. Tissue culture plastic ware and culture dishes were from Greiner (Greiner Bio-One, Kremsmünster, Austria).

\section{Cell counting}

Cell densities of epithelial cultures were determined as cell counts per area as described elsewhere (Pfaller et al., 1990; Lindl und Gstraunthaler, 2008).

\section{Cell extraction}

For Western blotting, cells were harvested in freshly prepared ice-cold RIPA-buffer (Feifel et al., 2002). The lysate was centrifuged at $10,000 \mathrm{~g}$ and $4^{\circ} \mathrm{C}$ for $5 \mathrm{~min}$. The supernatant was transferred into new tubes and stored at $-20^{\circ} \mathrm{C}$. The phosphatase inhibitors sodium orthovanadate and $\beta$-glycerophosphate were added to maintain the proteins in the phosphorylated state. The protease-inhibitor cocktail (Cat. No. P8340, Sigma-Aldrich) was added to prevent proteolysis. 
Protein Quantification Assay

The BCA $^{\mathrm{TM}}$ Protein Assay (Pierce, Rockford, IL, USA) is a detergent-compatible formulation based on bicinchoninic acid (BCA) for the colorimetric detection and quantitation of total protein.

\section{$S D S-P A G E$}

SDS-PAGE was performed under standard denaturing conditions using the Mini-PROTEAN 3 Electrophoresis System (Bio-Rad Laboratories, Inc.). Equal amounts of protein were loaded into each lane of $8 \%$ polyacrylamide gels for P-selectin and 9\% gels for ERK, respectively. Rainbow Marker (RPN 756, Amersham Life Science, GE Healthcare Europe, Freiburg, Germany) was used as a molecular weight standard.

\section{Western Blotting}

Gels were blotted immediately after electrophoresis onto polyvinylidene fluoride (PVDF) microporous membrane (Immobilon-P, Millipore). For immunodetection, membranes were blocked for $1 \mathrm{~h}$ with $5 \%(\mathrm{w} / \mathrm{v})$ non-fat dry milk in Trisbuffered saline $(\mathrm{pH} 7.6)$ at room temperature and processed according to the instructions of the antibody manufacturers. Anti-P-selectin antibody was from R\&D Systems, Abingdon, UK, and pan-ERK and anti-phospho-ERK1/2 antibodies were from New England Biolabs, Frankfurt, Germany. Visualization of blots was carried out with the Phototope ${ }^{\circledR}$-HRP Western Blot Detection System (LumiGLO ${ }^{\circledR}$ Cell Signaling, New England Biolabs).

\section{ELISA}

Growth factors bFGF, EGF, HGF, IGF-1, PDGF-AB, TGF- $\beta 1$ and VEGF were determined by commercially available immunoassays from R\&D Systems (Quantikine Assay kits for growth factors and Parameter Assay kits for hormones, R\&D Systems, Abingdon, UK).

\section{Viability Assay}

The WST-8 solution (Cat.No. 96992, Sigma-Aldrich) was added to cells grown in 6-well culture plates to a final concentration of $10 \%$ and incubated for $2 \mathrm{~h}$ at $37^{\circ} \mathrm{C}$. WST- 8 is reduced by dehydrogenases in cells to give a yellow-colored product (formazan), correlating to the number of metabolically active cells in the culture. Formazan formation was measured at $450 \mathrm{~nm}$.

\section{Scanning Electron Microscopy}

Control donor platelets and platelets after one cycle of freeze/ thawing were fixed in glutaraldehyde before filtration and subsequent preparation for scanning electron microscopy. In brief, control and activated platelet suspensions were pipetted into $0.1 \mathrm{M}$ sodium cacodylate $/ 2.5 \%$ glutaraldehyde, $\mathrm{pH}$ 7.4 in a $15 \mathrm{ml}$ test tube and incubated for $30 \mathrm{~min}$ on ice. Afterwards, platelets were sucked onto Millipore filters (pore size: 0.2 and $2.0 \mu \mathrm{m}$ ) that were mounted on a glass screen in a filtration unit. Dried filters were transferred to 6-well culture plates and covered with cacodylate/glutaraldehyde for 30 min. Thereafter, filters were washed with PBS, post-fixed with $\mathrm{OsO}_{4}$ for $30 \mathrm{~min}$ and washed again with PBS. Filters were then dehydrated with $30 \%, 50 \%, 75 \%$, and $95 \%$ methanol, each for $10 \mathrm{~min}$, and 3 times with $100 \%$ methanol at RT. After critical point drying, filters were sputtered with goldpalladium for scanning electron microscopy. SEM was carried out on a Jeol SM25 at $15 \mathrm{kV}$.

\section{Results}

\subsection{Effects of treatment on platelets}

\section{Morphological changes of platelets}

The morphological changes of human thrombocytes by freeze/ thawing were visualized by scanning electron microscopy. Representative photographs are displayed in Figure 1. Resting plate-
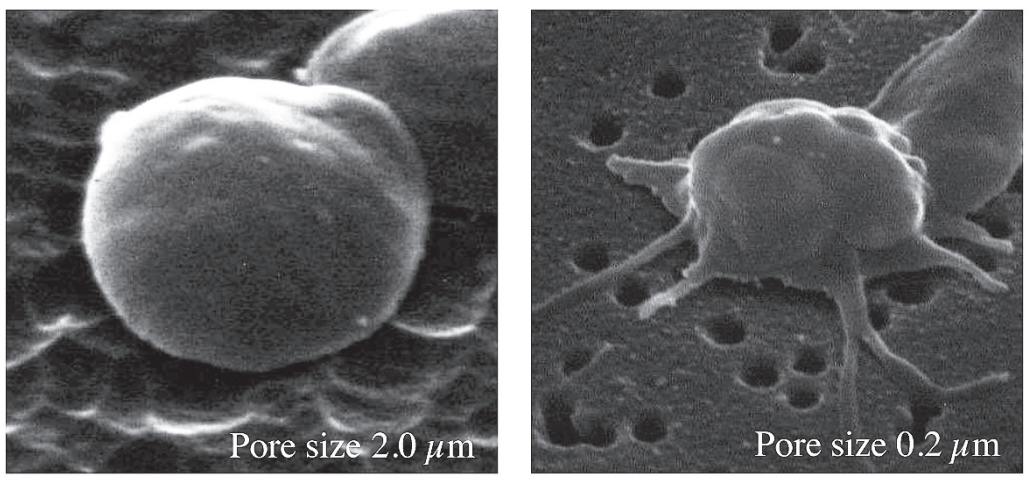

Fig. 1: Representative scanning electron micrographs of human thrombocytes on Millipore filters

Platelets in resting state (left), and after one cycle of freeze/thawing (right). Magnification 10,000 x (pore size $2.0 \mu \mathrm{m}$ for controls and 0.2 $\mu \mathrm{m}$ for activated platelets, respectively). 
Tab. 1: Growth factor contents in platelet lysates of different donor batches

Lysates were prepared from platelet concentrates containing $\sim 1.5 \times 10^{10}$ platelets $/ \mathrm{ml}$. For comparison, two human serum samples were analysed. n.d., not determined.

\begin{tabular}{|c|c|c|c|c|c|c|c|c|}
\hline & \multicolumn{7}{|c|}{ Growth Factors [ng/ml] } & \multirow{2}{*}{$\begin{array}{l}\text { Protein } \\
{[\mathrm{mg} / \mathrm{ml}]}\end{array}$} \\
\hline Lysate Samples & EGF & PDGF-AB & TGF- $\beta 1$ & HGF & IGF-1 & bFGF & VEGF & \\
\hline \# 56 & 11.63 & 57.28 & $1,179.7$ & 1.17 & 12.81 & 0.96 & 8.46 & 7.93 \\
\hline \# 69 & 15.34 & 76.48 & 533.2 & 1.38 & 16.70 & 1.04 & 3.47 & 5.88 \\
\hline \# 70 & 20.55 & 53.60 & $1,462.6$ & 1.46 & 8.90 & 1.05 & 10.63 & 9.03 \\
\hline \# 71 & 13.45 & 58.26 & 503.7 & 2.48 & 16.13 & 0.90 & 19.65 & 7.10 \\
\hline$\# 72$ & 16.69 & 46.34 & $1,272.5$ & 0.68 & 9.32 & 0.81 & 5.17 & 7.16 \\
\hline \# 73 & 14.27 & 51.88 & $1,084.3$ & 1.22 & 16.66 & 0.98 & 19.99 & 6.94 \\
\hline \# 108 & 13.44 & 89.26 & 518.1 & 1.65 & 25.89 & 1.33 & 1.27 & 9.34 \\
\hline$\# 134$ & 16.40 & 96.08 & 669.2 & 1.39 & n.d. & 2.55 & 1.36 & 12.34 \\
\hline \# 162 & 22.58 & 118.79 & 692.9 & 2.57 & n.d. & 2.97 & 1.12 & 10.55 \\
\hline \# 173 & 37.11 & 162.75 & 350.1 & 1.78 & n.d. & 4.52 & 1.01 & 15.63 \\
\hline \# 194 & 20.27 & 115.32 & 191.2 & 1.28 & n.d. & 4.41 & 5.32 & 14.15 \\
\hline Mean & 18.34 & 84.19 & 768.9 & 1.55 & 15.20 & 1.96 & 7.04 & 9.64 \\
\hline$\pm \mathrm{SD}$ & \pm 6.76 & \pm 34.86 & \pm 395.0 & \pm 0.53 & \pm 5.34 & \pm 1.36 & \pm 6.72 & \pm 3.04 \\
\hline \multirow{2}{*}{$\begin{array}{l}\text { Human } \\
\text { Serum }\end{array}$} & 1.52 & 4.64 & 46.87 & 0.80 & 75.96 & 0.0019 & 0.063 & 70.00 \\
\hline & 0.02 & 5.20 & 33.85 & 0.62 & 83.98 & 0.018 & n.d. & 70.00 \\
\hline
\end{tabular}

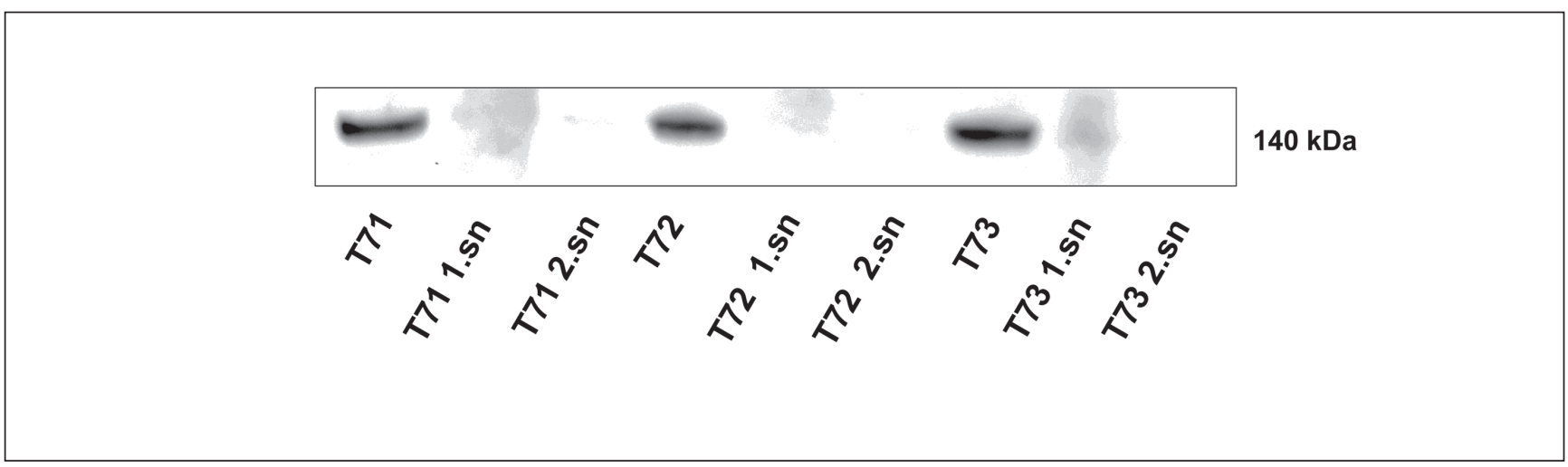

Fig. 2: Release of P-selectin (140 kDa) into platelet supernatant after freeze/thawing treatment

Western blot results of three representative lysates (\#71-\#73) are shown. 1.sn: first supernatant of resting platelets;

2.sn: second supernatant/wash fraction (after the washing step). T71-T73: Lysates of activated platelets show clear bands of P-selectin, indicative of the release of a-granule content from thrombocytes after freeze/thawing.

lets show a spheroid-discoid shape, while platelets after one cycle of freeze/thawing form long pseudopodia-like structures.

\section{$P$-selectin release after treatment}

In order to estimate the extent of $\alpha$-granule release, the amount of P-selectin in supernatants and platelet lysates was determined by Western blotting.

As shown in Figure 2, platelet lysates showed clear bands of P-selectin, while supernatants and wash fractions were negative. The data indicate that centrifugation and careful washing steps do not activate the platelets, and that freeze/thawing is sufficient for maximal release of $\alpha$-granule growth factors and P-selectin, respectively.

\subsection{Growth factor content of platelet lysates}

Concentration of different growth factors in platelet lysates Concentrations of $\alpha$-granule growth factors bFGF, EGF, HGF, IGF-1, PDGF-AB, TGF- $\beta 1$ and VEGF were quantified via enzyme-linked immunosorbent assay (ELISA) in 11 batches of platelet lysates (Kamath et al., 2001; Reed et al., 2000). Growth 
factor concentrations in lysate preparations are listed in Tab. 1. For comparison the levels of these factors determined in two unrelated human serum samples are given.

Platelet-derived growth factor (PDGF), a strong mitogen, is a major constituent of $\alpha$-granules. Concentrations found in platelet lysates are in the range of 50-100 $\mathrm{ng} / \mathrm{ml}$ (Tab. 1), indicating a 10- to 20-fold enrichment compared to normal serum levels. Epidermal growth factor (EGF), which is present in a number of serum-free culture media formulations in recommended concentrations of 1-100 ng/ml, is also a strong mitogen (Barnes and Sato, 1980; Gstraunthaler, 2003). Mean EGF contents in platelet lysates are in the range of $\sim 20 \mathrm{ng} / \mathrm{ml}$ compared to $\sim 1 \mathrm{ng} / \mathrm{ml}$ in human serum.

The different batches show concentration differences. These differences are likely attributable to individual donor factors, such as age and sex. Overall, the platelet lysates contained higher levels of $\alpha$-granule factors PDGF-AB, EGF, bFGF, HGF, TGF- $\beta 1$ and VEGF than the serum samples, whereas the level of the liver-derived serum marker IGF-1 was higher in the serum sample. Platelet lysates also showed a lower protein content than human serum, which is consistent with the removal of immunoglobulins and albumin in the washing procedure.

Based on these results, the following quality criteria for platelet lysates could be defined: high contents of PDGF-AB, VEGF, EGF, bFGF, and TGF- $\beta 1$, and low IGF- 1 content and low protein content $[\sim 10 \mathrm{mg} / \mathrm{ml}]$.

Growth factor stability during storage of platelet lysates To test the stability of platelet lysates during long-term storage, lysates were stored at $-20^{\circ} \mathrm{C}$ for five months. Every month, the content of EGF as a representative lysate growth factor marker was determined. Results show a strong stability of EGF in platelet lysates over the test period under this storage condition (Fig. 3).

\section{Growth-promoting effects of platelet lysates on cell lines}

For investigation of the growth-promoting effect of platelet lysates, cell culture experiments with a variety of human and animal cell lines were performed. Different concentrations of standardized platelet lysates $(1 \%, 5 \%$ and $10 \% \mathrm{v} / \mathrm{v})$ were added as serum replacement to serum-free basal culture media. Results from pilot experiments revealed that addition of 5\% was sufficient to promote cell proliferation (data not shown). The cells were cultured for up to 28 days, phase contrast micrographs were taken at day $3,7,14$, and 28 .

The results after 14 days with LLC-PK $_{1}$ and LLC-PK $_{1-}$ $\mathrm{FBPase}^{+}$porcine kidney cells, MDCK canine kidney cells, HK-2 human kidney cells, and OK opossum kidney cells (Gstraunthaler, 1988) are depicted in Figure 4. As can be seen, $5 \%$ platelet lysate supplementation fully supported growth and proliferation of the renal epithelial cell lines comparable to cultures with $10 \%$ FBS.

Raji cells (human lymphoblastoid cell line) and THP-1 cells (human acute monocytic leukemia cell line) were used as models for suspension-grown cultures (Fig. 5). 5\% Platelet lysate also fully supported the growth of the human suspension cell lines.

Furthermore, primary cultures of human chondrocytes, isolated from cartilage tissue in a tissue engineering laboratory, proliferated in media with $10 \%$ platelet lysates in human collagen-coated culture dishes. Human cornea epithelia were also successfully maintained in platelet lysate-supplemented media (data not shown).

For investigation whether cell attachment and growth can be enhanced by collagen-coating, we used collagen-coated cell dish-

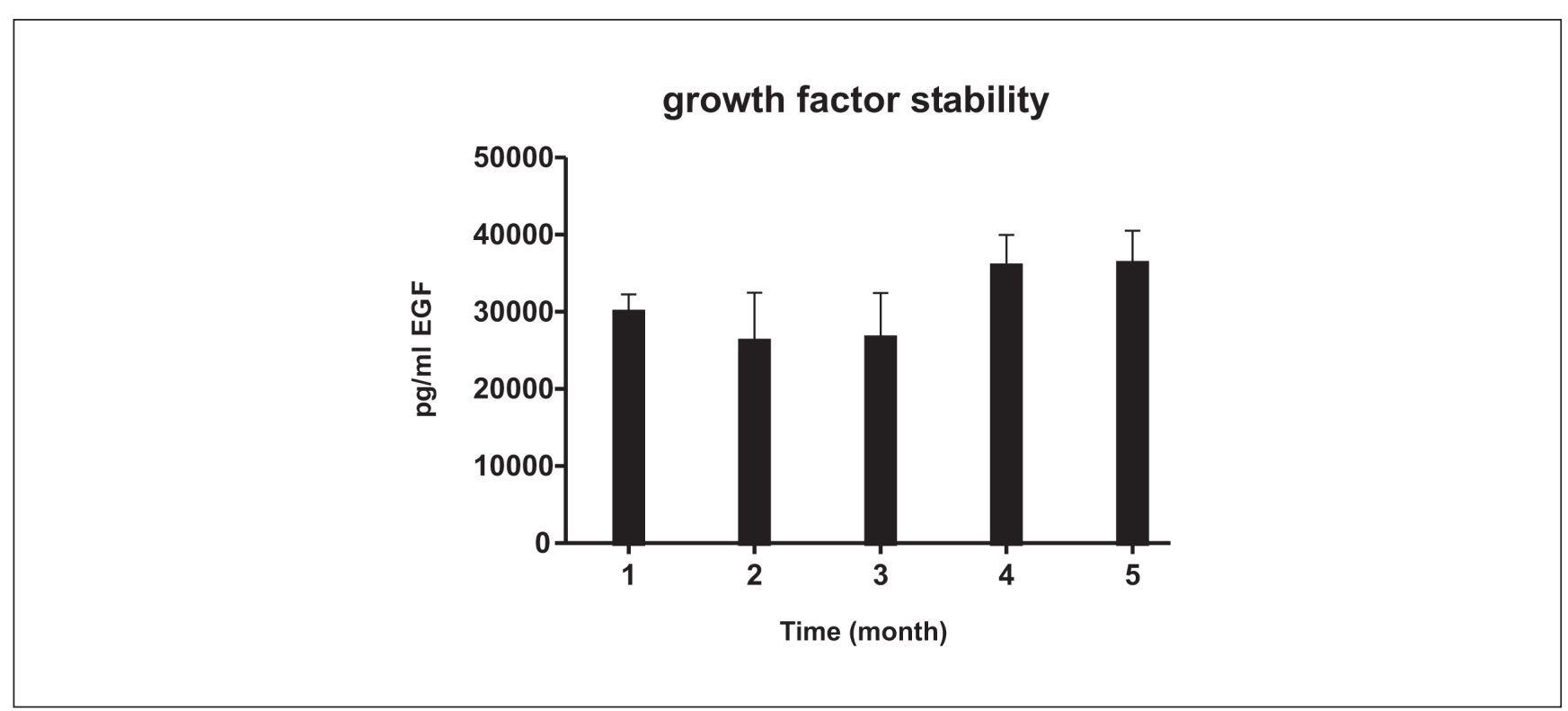

Fig. 3: Growth factor stability of EGF in platelet lysates stored at $-20^{\circ} \mathrm{C}$ for five months

Values are expressed as means $\pm \mathrm{SD}$ of four lysate samples. 

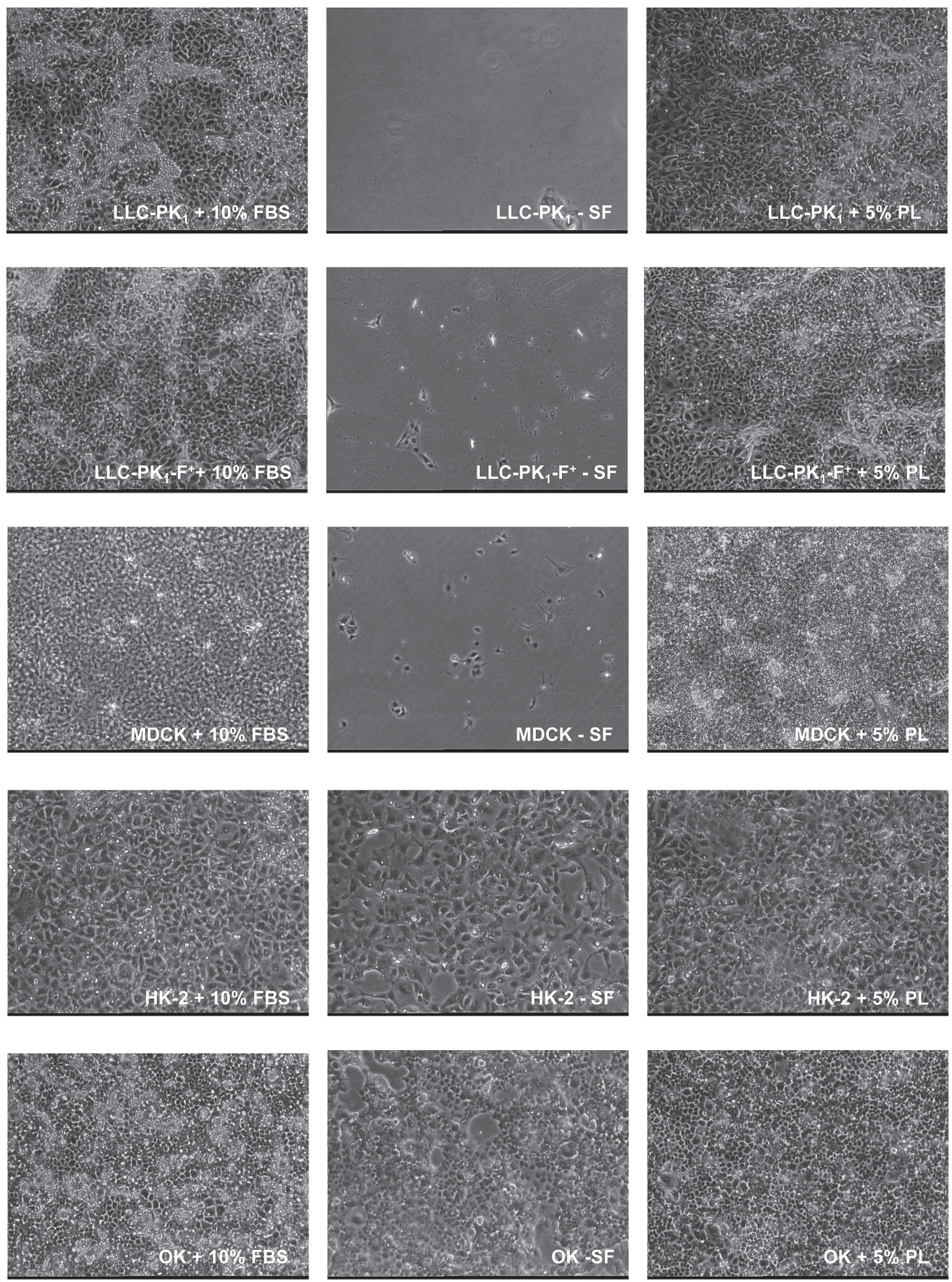

Fig. 4: Cell growth experiments using animal and human renal epithelial cell lines (LLC-PK 1 pig kidney cell line, LLC-PK $1-F^{+}$strain, MDCK Madin-Darby canine kidney cell line, HK-2 human kidney cell line, OK opossum kidney cells) Cells were grown on DMEM with either $10 \%$ FBS, without any supplementation (serum-free, SF) or with the addition of $5 \%$ platelet lysate $(\mathrm{PL})$. Phase contrast micrographs were taken after 14 days in culture. Magnification $20 \mathrm{x}$. 

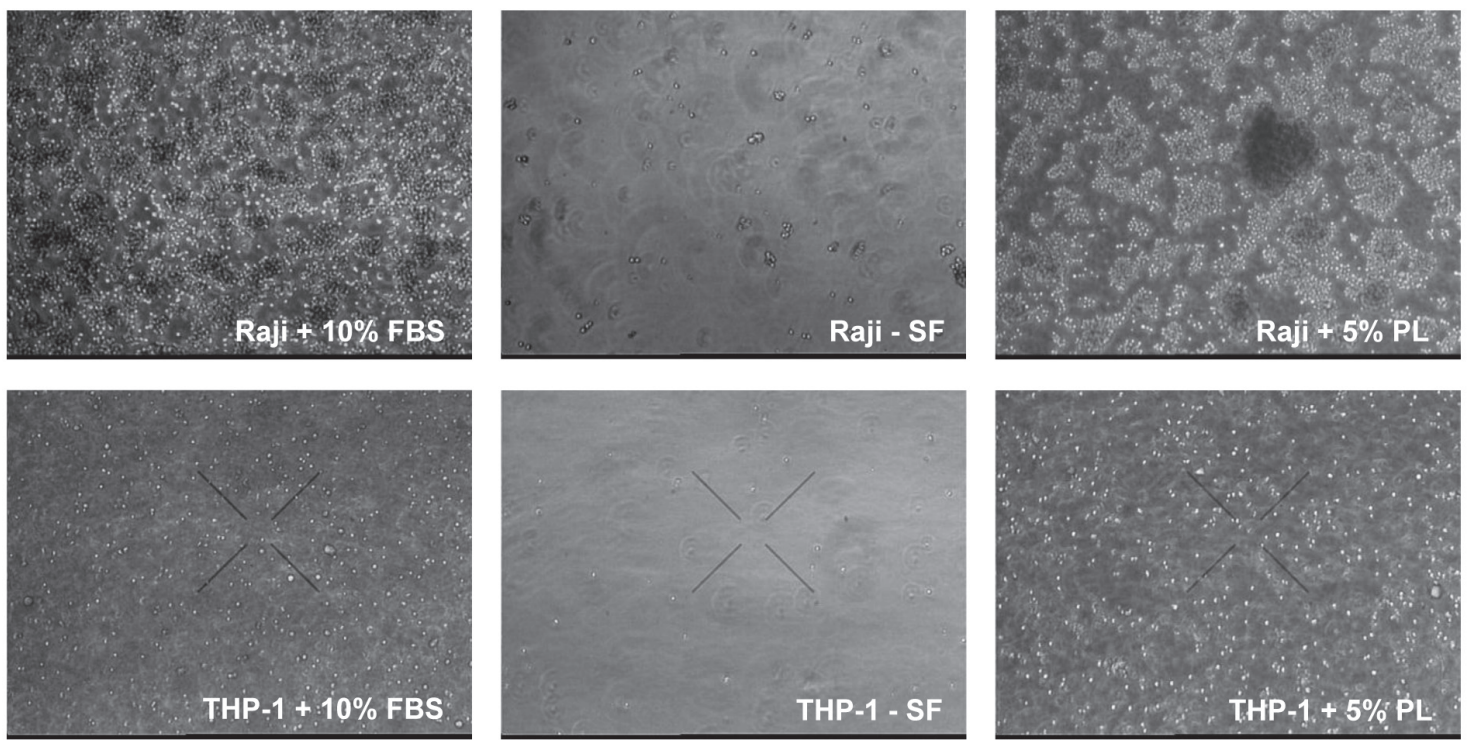

Fig. 5: Cell growth experiment using human cell lines grown in suspension culture (Raji, a lymphoblastoid cell line derived from a Burkitt lymphoma and THP-1, a human acute monocytic leukemia cell line) Cells were grown in RPMI-1640 medium with either 10\% FBS, without any supplementation (serum-free, SF) or with the addition of $5 \%$ platelet lysate (PL). Phase contrast micrographs were taken after 14 days in culture. Magnification $20 \mathrm{x}$.

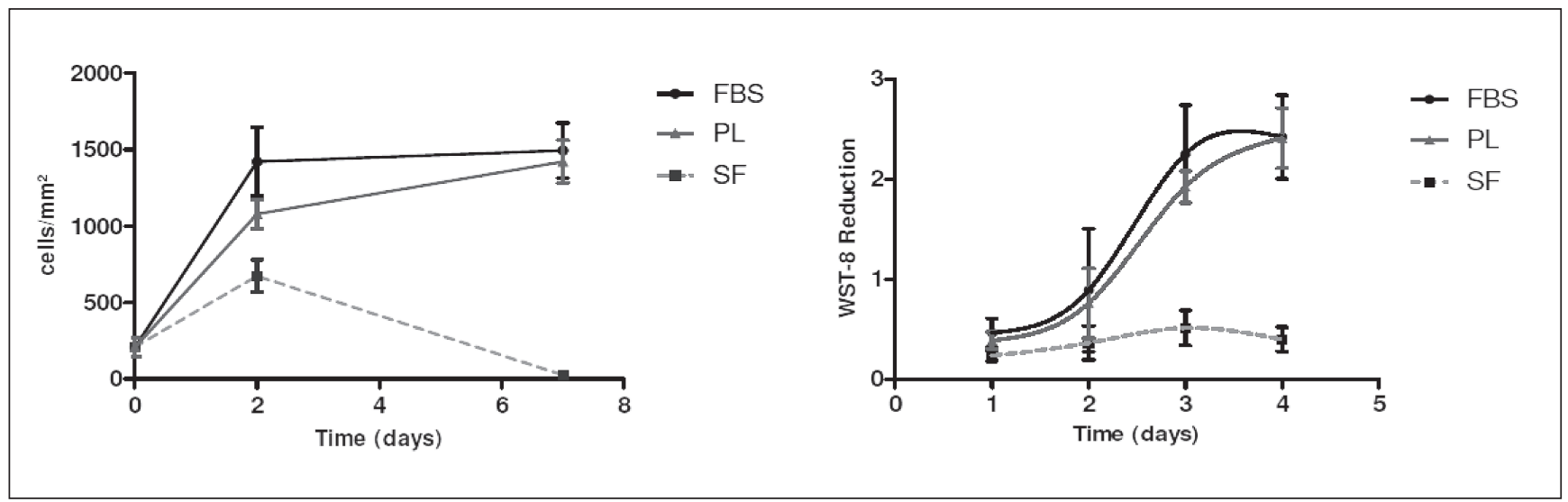

Fig. 6: Growth curves of LLC-PK 1 (left) and MDCK cells (right) under FBS or PL supplementation

Cultures were grown on DMEM with either 10\% FBS (black), without any supplementation (serum-free, SF, dashed line) or with the addition of $5 \%$ platelet lysate (PL, grey). Left panel: Cell counts (cells $/ \mathrm{mm}^{2}$ ) of LLC-PK 1 cultures; right panel: WST-8 assay of MDCK cells. Data are expressed as means \pm SD of three independent experiments.

es in comparison to tissue culture-treated polystyrol dishes. Coated dishes with proteins of the extracellular matrix are frequently used in serum-free or serum-reduced cell cultivation for improvement of cell attachment and growth, because serum-free media partially contain lower attachment proteins than FBS containing media (Gstraunthaler, 2003; Lindl und Gstraunthaler, 2008). For MDCK cells collagen-coating did not improve cell proliferation, whereas for LLC-PK1 cells collagen-coating could enhance the growth rate in platelet lysate containing media (data not shown).

\subsection{Cell growth promotion by platelet lysates}

Growth curves of LLC-PKI and MDCK cells

To quantify the cell growth experiments, representative growth curves for LLC-PK 1 and MDCK cultures were determined by in situ-cell counting for LLC-PK 1 and WST-8 proliferation assay for MDCK cultures, respectively (Lindl und Gstraunthaler, 2008). The results in Figure 6 clearly revealed that in both methods the growth-promoting effect of $5 \%$ platelet lysate is almost identical to that of $10 \%$ FBS. 

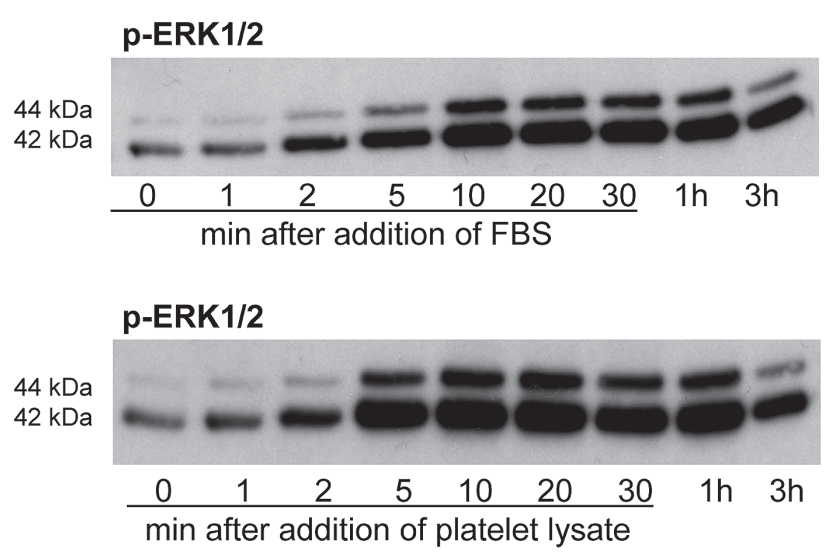

p-ERK1/2

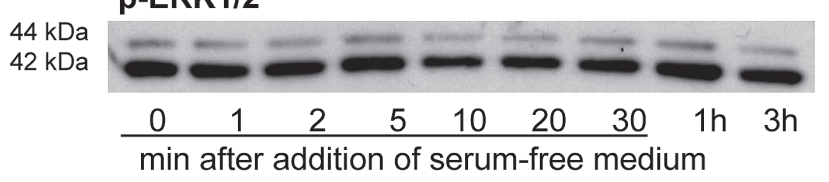

ERK2 total protein control (pan ERK2)

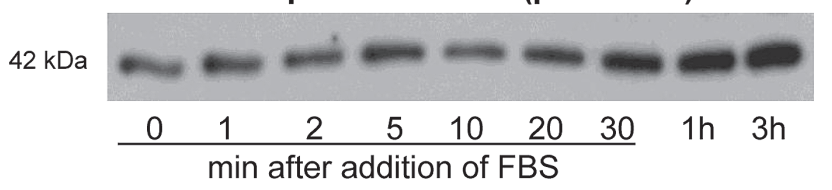

Fig. 7: Western blot analysis of specific ERK1/2 phosphorylation, and thus activation, in whole cell extracts of LLC-PK 1 cells upon addition of FBS and platelet lysate, respectively

Subconfluent LLC-PK 1 cultures were serum-depleted for $24 \mathrm{~h}$ and then stimulated by the addition of $10 \%$ FBS or $5 \%$ PL (upper panels). At the time points indicated, cells were harvested and subjected to SDS-PAGE and Western blotting. Addition of serum-free medium served as a control. Equal protein loading was assessed by staining with a pan ERK2 antibody (lower panels).

Stimulation of ERK1/2 MAP kinases

In order to visualize the mitogenic effect of growth factors in platelet lysates, phospho-specific ERK Western blots using LLC-PK $_{1}$ cells were performed. For this blotting technique, Phospho-specific antibodies against ERK1 and ERK2 were used. ERK1 and ERK2 are members of the MAPK family, which belong to a specific transcriptional activation cascade involved in many cell regulating processes. ERK1/2 are activated by specific phosphorylation that initiates the transcription of genes leading to cell growth and proliferation (Feifel et al., 2002; Schramek, 2002).

The Western blots presented in Figure 7 show the induction of ERK1/2 phosphorylation in FBS- or platelet lysate-stimulated LLC-PK $_{1}$ cells. LLC-PK 1 cultures were serum-deprived for $24 \mathrm{~h}$ and then stimulated by the addition of $10 \% \mathrm{FBS}, 5 \%$ platelet lysate or serum-free medium without any supplementation with growth factors or hormones. The bands show distinct phosphorylation of ERK1 and ERK2. Phosphorylation, and thus ERK activation starts about two minutes after stimulation, with a peak after ten minutes and a decrease to basal values after 3 h. Platelet lysate-treated cells show a slightly higher stimulation after 5 min compared to FBS. Addition of serum-free medium to serum-deprived cultures did not stimulate the MAP kinases.

\section{Discussion}

The 3Rs are guiding principles for the use of animals in research and testing, first described by Russell and Burch more than 50 years ago (Balls, 2010; Balls et al., 1995). Their intention was to reduce pain and fear of experimental animals defined by the $3 \mathrm{Rs}$ concept (Refine, Reduce, and Replace). Refinement means any decrease in the incidence or severity of inhumane procedures. Reduction means the reduction in the numbers of animals used to obtain information of a given amount and precision. Replacement means the substitution of any experimental animals by in vitro and/or in silico methods (Fletcher et al., 2011; Mahadevan et al., 2011).

The search for alternatives to replace fetal bovine serum (FBS) has become a major goal in the field of cell and tissue 
culture. The efforts to develop a substitute for FBS are primarily based on two intentions. On the one hand, harvest and production of FBS is ethically problematic, and thus a replacement is needed (Brunner et al., 2010; Jochems et al., 2002; van der Valk et al., 2004). On the other hand, the rapidly expanding fields of in vitro cell and tissue culture, biomedical tissue engineering, and (adult) stem-cell therapy require defined, safe, and animal component-free culture conditions (Atala, 2007; van der Valk et al., 2010). In case of the scientific aspect the substitution of sera would lead to a better quality and reproducibility of experimental data as suggested by Good Cell Culture Practice (Balls et al., 2006; Coecke et al., 2005; Gstraunthaler, 2006, 2010; Hartung et al., 2002). Serum or FBS is known to be a chemically ill-defined supplement, bearing qualitative and quantitative variations that exhibit a possible source of microbial contamination with fungi, bacteria, viruses, mycoplasma, and prions (Brunner et al., 2010; Gstraunthaler, 2003; van der Valk et al., 2010).

More than 30 years ago (Hayashi and Sato, 1976) researchers started efforts to find alternatives to animal serum (Brunner et al., 2010; Gstraunthaler, 2003; Lindl und Gstraunthaler, 2008). Since then a whole range of substitutes have become commercially available or are still under investigation, including chemically-defined media substitutes, tissue extracts (e.g., pituitary extracts), ocular fluid (Filipic et al., 2002), bovine milk fractions or bovine colostrum (Belford et al., 1995), plant extracts (vegetal serum) (Pazos et al., 2004), and platelet lysates (Johansson et al., 2003).

Serum, rather than plasma, promotes the growth and proliferation of cultured cells (Gospodarowicz and Ill, 1980). In the past, much effort was spent to identify the factors in serum that stimulate cell growth in vitro. An important step forward in the search for serum growth factors has been the finding that the most potent mitogenic factors present in serum are derived from activated thrombocytes (Balk et al., 1981; Gospodarowicz and Ill, 1980).

Platelets are known to be a rich source of growth factors (Marx et al., 1998; Weibrich et al., 2002; Anitua et al., 2004), thus suggesting platelet lysates as a valuable animal serum substitute. Platelet lysates were tested on mesenchymal stem cells (MSCs), concluding that the lysates were more efficient in terms of costs and proliferation rate than using exogenous recombinant growth factors and retained their immunosuppressive (Doucet et al., 2005) as well as their differentiation capability (Lange et al., 2007).

Donor platelets have a shelf life of five days for therapeutic applications, but they retain all growth factors for at least three weeks (Chan et al., 2005). Outdated donor platelets obtained by apheresis were separated from the plasma or platelet additive solution (PAS) (Shanwell et al., 2003) by centrifugation and gentle resuspension in physiological saline. The counting of platelets by the CASY ${ }^{\circledR}$ Cell Counter revealed a marginal loss of platelets during the preparation procedure. The platelet suspension yielded an average platelet count of $1.5 \times 10^{10} / \mathrm{ml}$.

Pilot experiments established freeze/thawing as the method of choice for enriching $\alpha$-granule derived components. Besides being the most economic method, a further advantage of this physical method is that the platelet lysates do not contain traces of biochemical activators.

The morphological status of platelets was visualized by scanning electron microscopy (SEM), and platelet degranulation was determined by specific P-selectin release (Fig. 1, 2). P-selectin, also known as CD62P or PADGEM is a transmembrane protein of the $\alpha$-granule that is released together with the granule content into the supernatant (McEver, 1995; Blann and Lip, 1997).

The lysates obtained by freeze/thawing showed high concentrations of the $\alpha$-granule derived growth factors EGF, bFGF, HGF, PDGF-AB, TGF- $\beta 1$, and VEGF. As expected, the content of liver-derived IGF-1 was lower in the lysates than in human serum samples. The low protein concentration of about $10 \mathrm{mg} /$ $\mathrm{ml}$ suggests a low concentration of extraneous material, thus reducing the risk of causing immunological reactions.

Platelet-derived growth factor concentrations have also been investigated by several other laboratories (Christgau et al., 2006; Cognasse et al., 2006; Doucet et al., 2005; Frechette et al., 2005; Gruber et al., 2002; Kaps et al., 2002; Lacoste et al., 2003; Ogino et al., 2006; Schallmoser et al., 2007; Shen et al., 2006; Weibrich et al., 2002; Zimmermann et al., 2003). The results of these analyses are not comparable with our results, because of different preparation methods: All except El Backly et al. and Gruber et al. (El Backly et al., 2011; Gruber et al., 2002) stored platelets in serum, which also contains growth factors, and/or in platelet additive solution.

We further assessed the stability of the growth factors in the platelet supernatant during long-term storage. EGF was chosen as a marker as it is commonly used in cell culture media. Results showed that EGF is stable at $-20^{\circ} \mathrm{C}$ for at least five months (Fig. 3).

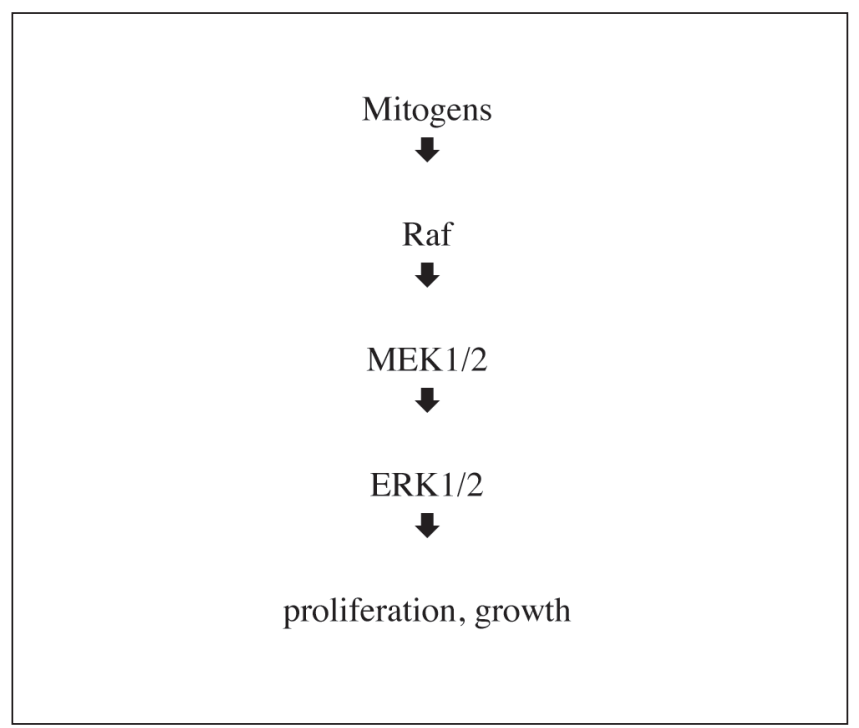

Fig. 8: MAP kinase signaling cascade leading to cell proliferation

Mitogens (e.g., EGF, whole serum) activate Raf, which phosporylates MEK (MAPK/ERK kinase), that leads to a specific phosphorylation of ERK1/2. As a result, the terminal kinases activate downstream transcription factors that initiate specific gene expression programs for cell division and proliferation, respectively. 
In order to biochemically determine the proliferative potential of platelet lysates, the stimulation of extracellular signal-regulated MAP kinase (ERK1/2) by platelet lysates was determined. ERK1/2, activated by extracellular stimuli such as growth factors or FBS, are part of the MAPK (mitogenactivated protein kinase) signaling network that regulates growth, proliferation, differentiation, and survival of almost all cells (Treisman, 1996; Chang and Karin, 2001; Pearson et al., 2001) (Fig. 8). Addition of 5\% platelet lysates to serumstarved, quiescent LLC-PK 1 cells induced phosphorylation, and thus activation, of ERK1/2 within minutes. The activation potential of platelet lysates was comparable with that of FBS (Figure 7). In recent functional studies, LLC-PK 1 and MDCK epithelia cultured in the presence of platelet lysates generated a transepithelial electrical resistance (TEER) comparable to FBS (manuscript in preparation). TEER is a sensitive indicator for epithelial differentiation, assembly of cell-cell junctional complexes, and vectorial transepithelial solute transport across cultured epithelial layers (Gstraunthaler, 1988).

Results from our experiments indicate a high potential for platelet lysates as a growth-promoting culture media substitute for a multitude of cell lines. Moreover, the application of platelet lysate would minimize the risk of microbial contaminations (Kuznetsov et al., 2000), reduce immunological reactions (Bartholomew et al., 2002), and be more economical than FBS or recombinant growth factors (Doucet et al., 2005).

Aside from use as a universal serum replacement, platelet lysate could also serve as a substitute for autologous human serum in tissue engineering and biomedical cell therapy (Klimanskaya et al., 2008; Minuth et al., 1998; Stock and Vacanti, 2001). Tissue engineering requires authorized GMP (Good Manufacturing Practice) protocols and autologous culture conditions for the cultivation and expansion of human donor cells (Halme and Kessler, 2006; McDevitt and Palecek, 2008). In order to avoid additional stress for patients by extracting a 400 $\mathrm{ml}$ unit of blood for autologous serum production, this could be overcome with the use of platelet apheresis and subsequent platelet lysate production.

In case of platelet transfusion therapy, allogenic platelet concentrates from voluntary donors with blood groups and Rhesus factors identical with the recipients are applied. Thus, also for cultivation and expansion of donor cells, it could be feasible to use allogenic platelet lysate with matching blood group and Rhesus factor (Kaufman, 2009; Shehata et al., 2009; Stroncek and Rebulla, 2007). In this context, the collaboration with a tissue engineering laboratory showed that our platelet lysate could support the growth of human chondrocytes. Also, human corneal epithelia were successfully maintained in platelet lysate-supplemented media (data not shown).

ESAC, the ECVAM Scientific Advisory Committee, recently endorsed a statement that strongly recommends - whenever possible - the use of non-animal alternatives to FBS in new in vitro test methods: "For methods forwarded to ECVAM for validation/prevalidation where this is not fulfilled, a justification for future use must be provided, including measures taken to seek non-animal alternatives to FBS" (ESAC, 2008).

Thus, platelet lysates can serve as a full "Replacement" in terms of the 3Rs and as a promising substitute for FBS in all in vitro methodologies, like cell and tissue culture, in vitro toxicity studies, prevalidation and validation, tissue engineering, and cell therapy (Leist et al., 2008).

\section{References}

Abrams, C. S. (2005). Intracellular signaling in platelets. Curr. Opin. Hematol. 12, 401-405.

Anitua, E., Andia, I., Ardanza, B., et al. (2004). Autologous platelets as a source of proteins for healing and tissue regeneration. Thromb. Haemost. 91, 4-15.

Atala, A. (2007). Engineering tissues, organs and cells. J. Tissue Eng. Regen. Med. 1, 83-96.

Balk, S. D., Levine, S. P., Young, L. L., et al. (1981). Mitogenic factors present in serum but not in plasma. Proc. Natl. Acad. Sci. USA 78, 5656-5660.

Balls, M., Goldberg, A. M., Fentem, J. H., et al. (1995). The three Rs: the way forward. The report and recommendations of ECVAM Workshop 11. ATLA 23, 838-866.

Balls, M., Coecke, S., Bowe, G., et al. (2006): The importance of Good Cell Culture Practice (GCCP). ALTEX 23, Spec. Issue, 270-273.

Balls, M. (2010). The principles of humane experimental technique: timeless insights and unheeded warnings. ALTEX 27, Spec. Issue, 19-23.

Barano, J. L. S. and Hammond, J. H. (1985). Serum-free medium enhances growth and differentiation of cultured pig granulosa cells. Endocrinol. 116, 51-58.

Barnes, D. and Sato, G. (1980). Methods for growth of cultured cells in serum-free medium. Anal. Biochem. 102, 255-270.

Bartholomew, A., Sturgeon, C., Siatskas, M., et al. (2002). Mesenchymal stem cells suppress lymphocyte proliferation in vitro and prolong skin graft survival in vivo. Exp. Hematol. $30,42-48$.

Belford, D. A., Rogers, M.-L., Regester, G. O., et al. (1995). Milk-derived growth factors as serum supplements for the growth of fibroblasts and epithelial cells. In Vitro Cell. Dev. Biol. 31, 752-760.

Bernardo, M. E., Avanzini, M. A., Perotti, C., et al. (2007). Optimization of in vitro expansion of human multipotent mesenchymal stromal cells for cell-therapy approaches: further insights in the search for fetal calf serum substitute. J. Cell. Physiol. 211, 121-130.

Bieback, K., Hecker, A., Kocaömer, A., et al. (2009). Human alternatives to fetal bovine serum for the expansion of mesenchymal stromal cells from bone marrow. Stem Cells 27, 2331-2341.

Blann, A. D. and Lip, G. Y. H. (1997). Hypothesis: Is soluble Pselectin a new marker of platelet activation? Atherosclerosis 128, 135-138.

Brunner, D., Frank, J., Appl, H., et al. (2010). Serum-free cell culture: the serum-free media interactive online database. ALTEX 27, 53-62.

Burnouf, T., Tseng, Y. H., Kuo, Y. P., and Su, C. Y. (2008). Solvent/detergent treatment of platelet concentrates enhances the release of growth factors. Transfusion 48, 1090-1098. 
Chan, R. K., Liu P., Lew, D. H., et al. (2005). Expired liquid preserved platelet releasates retain proliferative activity. J. Surg. Res. 126, 55-58.

Chang, L. and Karin, M. (2001). Mammalian MAP kinase signalling cascades. Nature 410, 37-40.

Christgau, M., Moder D., Hiller, K. A., et al. (2006). Growth factors and cytokines in autologous platelet concentrate and their correlation to periodontal regeneration outcomes. $J$. Clin. Periodontol. 33, 837-845.

Coecke, S., Balls, M., Bowe, G., et al. (2005). Guidance on Good Cell Culture Practice. A report of the second ECVAM task force on Good Cell Culture Practice. ATLA 33, 261-287.

Cognasse, F., Boussoulade F., Chavarin, P., et al. (2006). Release of potential immunomodulatory factors during platelet storage. Transfusion 46, 1184-1189.

Doucet, C., Ernou, I., Zhang, Y., et al. (2005). Platelet lysates promote mesenchymal stem cell expansion: a safety substitute for animal serum in cell-based therapy applications. $J$. Cell. Physiol. 205, 228-236.

El Backly, R., Ulivi, V., Tonachini, L., et al. (2011). Platelet lysate induces in vitro wound healing of human keratinocytes associated with a strong proinflammatory response. Tissue Eng. A 17, 1787-1800.

ESAC (2008). Statement on the use of FCS and other animalderived supplements. http://ecvam.jrc.it/index.cfm?voce $=$ s\&i dvoce $=27 \&$ idmm $=4 \&$ idsm $=27$

Falkner, E., Appl, H., Eder, C., et al. (2006). Serum free cell culture: The free access online database. Toxicol. In Vitro 20, 395-400.

Feifel E., Obexer P., Andratsch M., et al. (2002). p38 MAPK mediates acid-induced transcription of PEPCK in LLC-PK ${ }^{-}$ FBPase $^{+}$cells. Am. J. Physiol. Renal Physiol. 283, F678F688.

Filipic, B., Shehata, M., Toth, S., et al. (2002). Novel serum replacement based on bovine ocular fluid: a useful tool for cultivation of different animal cells in vitro. ALTEX 19, 15-20.

Fletcher, K., Shah, R. R., Thomas, A., et al. (2011). Novel approaches to assessing cardiac safety - proceedings of a workshop: regulators, industry and academia discuss the future of in silico cardiac modelling to predict the proarrhythmic safety of drugs. Drug Saf. 34, 439-443.

Frechette, J. P., Martineau, I., and Gagnon, G. (2005). Plateletrich plasmas: growth factor content and roles in wound healing. J. Dent. Res. 84, 434-439.

Gachet, C. (2000). Platelet activation by ADP: the role of ADP antagonists. Ann. Med. 32, Suppl. 1, 15-20.

Gospodarowicz, D. and Ill, C. R. (1980). Do plasma and serum have different abilities to promote cell growth? Proc. Natl. Acad. Sci. USA 77, 2726-2730.

Gruber, R., Varga, F., Fischer, M. B., and Watzek, G. (2002). Platelets stimulate proliferation of bone cells: involvement of platelet-derived growth factor, microparticles and membranes. Clin. Oral Implants Res. 13, 529-535.

Gstraunthaler, G. J. (1988). Epithelial cells in tissue culture (Review). Renal Physiol. Biochem. 11, 1-42.

Gstraunthaler, G., Holcomb, T., Feifel, E., et al. (2000). Differential expression and acid-base regulation of glutaminase
mRNAs in gluconeogenic LLC-PK 1 -FBPase ${ }^{+}$cells. Am. J. Physiol. Renal Physiol. 278, F227-237.

Gstraunthaler, G. (2003). Alternatives to the use of fetal bovine serum: serum-free cell culture. ALTEX 20, 275-281.

Gstraunthaler, G. (2006). Standardization in cell and tissue culture - the need for specific GLP guidelines in the cell culture laboratory (Good Cell Culture Practice - GCCP). ALTEX 23, Spec. Issue, 274-277.

Gstraunthaler, G. (2010). The Bologna Statement on Good Cell Culture Practice (GCCP) - 10 years later. ALTEX 27, Spec. Issue, 141-146.

Hartung, T., Balls, M., Bardouille, C., et al. (2002). Good Cell Culture Practice. ECVAM Good cell culture practice task force report 1. ATLA 30, 407-414.

Hayashi, I. and Sato, G.-H. (1976). Replacement of serum by hormones permits growth of cells in a defined medium. $\mathrm{Na}$ ture 259, 132-134.

Jochems, C. E. A., van der Valk, J. B. F., Stafleu, F. R., and Baumans, V. (2002). The use of fetal bovine serum: ethical or scientific problem? ATLA 30, 219-227.

Johansson, L., Klinth, J., Holmqvist, O., and Ohlson, S. (2003). Platelet lysate: a replacement for fetal bovine serum in animal cell culture? Cytotechnol. 42, 67-74.

Kamath, S., Blann, A. D., and Lip, G. Y. H. (2001). Platelet activation: assessment and quantification. Eur. Heart J. 22, 1561-1571.

Kaps, C., Loch, A., Haisch, A., et al. (2002). Human platelet supernatant promotes proliferation but not differentiation of articular chondrocytes. Med. Biol. Eng. Comput. 40, 485-490.

Kaufman, R. M. (2009). Platelet ABO matters. Transfusion 49, $5-7$.

King, S. M. and Reed, G. L. (2002). Development of platelet secretory granules. Sem. Cell Dev. Biol. 13, 293-302.

Klimanskaya, I., Chung, Y., Meisner, L., et al. (2005). Human embryonic stem cells derived without feeder cells. Lancet 365, 1636-1641.

Kuznetsov, S. A., Mankani, M. H., and Robey, P. G. (2000). Effect of serum on human bone marrow stromal cells: ex vivo expansion and in vivo bone formation. Transplantation 70, 1780-1787.

Lacoste, E., Martineau, I., and Gagnon, G. (2003). Platelet concentrates: effects of calcium and thrombin on endothelial cell proliferation and growth factor release. J. Periodontol. 74, 1498-1507.

Lange, C., Cakiroglu, F., Spiess, A.-N., et al. (2007). Accelerated and safe expansion of human mesenchymal stromal cells in animal serum-free medium for transplantation and regenerative medicine. J. Cell. Physiol. 213, 18-26.

Leist, M., Bremer, S., Brundin, P., et al. (2008). The biological and ethical basis of the use of human embryonic stem cells for in vitro test systems or cell therapy. ALTEX 25, 163-190.

Lindl, T. and Gstraunthaler, G. (2008). Zell- und Gewebekultur. Von den Grundlagen zur Laborbank. Heidelberg: Spektrum Akademischer Verlag.

Maguire, P. B. and Fitzgerald, D. J. (2003). Platelet proteomics. J. Thromb. Haemost. 1, 1593-1601.

Mahadevan, B., Snyder, R. D., Waters, M. D., et al. (2011). Ge- 
netic toxicology in the $21^{\text {st }}$ century: Reflections and future directions. Environ. Mol. Mutagen. 52, 339-354.

Martin, M. J., Muotri, A., Gage, F., and Varki, A. (2005). Human embryonic stem cells express an immunogenic nonhuman sialic acid. Nat. Med. 11, 228-232.

Marx, R. E., Carlson, E. R., Eichstaedt, R. M., et al. (1998). Platelet-rich plasma: Growth factor enhancement for bone grafts. Oral Surg. Oral Med. Oral Pathol. Oral Radiol. Endod. 85, 638-646.

McDevitt, T. C. and Palecek, S. P. (2008). Innovation in the culture and derivation of pluripotent human stem cells. Curr. Opin. Biotechnol. 19, 527-533.

McEver, R. P. (1995). Regulation of function and expression of P-selectin. Agents Actions, Suppl. 47, 117-119.

Minuth, W. W., Sittinger, M., and Kloth, S. (1998). Tissue engineering: generation of differentiated artificial tissues for biomedical applications. Cell Tissue Res. 291, 1-11.

Ogino, Y., Ayukawa, Y., Kukita, T., and Koyano, K. (2006). The contribution of platelet-derived growth factor, transforming growth factor-beta1, and insulin-like growth factor-I in platelet-rich plasma to the proliferation of osteoblast-like cells. Oral Surg. Oral Med. Oral Pathol. Oral Radiol. Endod. 101, 724-729.

Park, D. H. and Eve, D. J. (2009). Regenerative medicine: advances in new methods and technologies. Med. Sci. Monit. 15, RA233-251.

Pazos, P., Boveri, M., Gennari, A., et al. (2004). Culturing cells without serum: Lessons learnt using molecules of plant origin. ALTEX 21, 67-72.

Pearson, G., Robinson, F., Beers Gibson, T., et al. (2001). Mitogen-activated protein (MAP) kinase pathways: regulation and physiological functions. Endocr. Rev. 22, 153-183.

Pfaller, W., Gstraunthaler, G., and Loidl, P. (1990). Morphology of the differentiation and maturation of LLC-PK1 epithelia. $J$. Cell. Physiol. 142, 247-254.

Reed, G. L., Fitzgerald, M. L., and Polgar, J. (2000). Molecular mechanisms of platelet exocytosis: insights into the "secrete" life of thrombocytes. Blood 96, 3334-3342.

Rendu, F. and Brohard-Bohn, B. (2001). The platelet release reaction: granules' constituents, secretion and functions. Platelets 12, 261-273.

Schallmoser, K., Bartmann, C., Rohde, E., et al. (2007). Human platelet lysate can replace fetal bovine serum for clinical-scale expansion of functional mesenchymal stromal cells. Transfusion $47,1436-1446$.

Schramek, H. (2002). MAP kinases: from intracellular signals to physiology and disease. News Physiol. Sci. 17, 62-67.

Shanwell, A., Falker, C., and Gullikkson, H. (2003). Storage of platelets in additive solutions: the effects of magnesium and potassium on the release of RANTES, beta-thromboglobulin, platelet factor 4 and interleukin-7, during storage. Vox Sang. 85, 206-212.

Shehata, N., Tinmouth, A., Naglie, G. et al. (2009). ABO-identical versus nonidentical platelet transfusion: a systematic review. Transfusion 49, 2442-2453.
Shen, E. C., Chou T. C., Gau, C. H., et al. (2006). Releasing growth factors from activated human platelets after chitosan stimulation: a possible bio-material for platelet-rich plasma preparation. Clin. Oral Implants Res. 17, 572-578.

Spreafico, A., Chellini, F., Frediani, B., et al. (2009). Biochemical investigation of the effects of human platelet releasates on human articular chondrocytes. J. Cell. Biochem. 108, 1153-1165.

Stock, U. A. and Vacanti, J. P. (2001). Tissue engineering: current state and prospects. Annu. Rev. Med. 52, 443-451.

Stroncek, D. F. and Rebulla, P. (2007). Platelet transfusions. Lancet 370, 427-438.

Taupin, P. (2006). Derivation of embryonic stem cells for cellular therapy: challenges and new strategies. Med.Sci.Monit. 12, RA75-78.

Taupin, P. (2007). Stem cells engineering for cell-based therapy. J. Neural. Eng. 4, R59-63.

Treisman, R. (1996). Regulation of transcription by MAP kinase cascades. Curr. Opin. Cell Biol. 8, 205-215.

van der Valk, J., Mellor, D., Brands, R., et al. (2004). The humane collection of fetal bovine serum and possibilities for serum-free cell and tissue culture. Toxicol. In Vitro 18, 1-12. van der Valk, J., Brunner, D., De Smet, K., et al. (2010). Optimization of chemically defined cell culture media - replacing fetal bovine serum in mammalian in vitro methods. Toxicol. In Vitro 24, 1053-1063.

Weibrich, G., Kleis, W. K., Hafner, G., and Hitzler, W. E. (2002). Growth factor levels in platelet-rich plasma and correlations with donor age, sex, and platelet count. J. Craniomaxillofac. Surg. 30, 97-102.

Zimmermann, R., Arnold, D., Strasser, E., et al. (2003). Sample preparation technique and white cell content influence the detectable levels of growth factors in platelet concentrates. Vox Sang. 85, 283-289.

\section{Acknowledgements}

The authors thank Mrs. Edna Nemati for the superb scanning electron microscopy work. This study was generously supported by the Pollux Private Foundation.

\section{Correspondence to}

Gerhard Gstraunthaler, PhD

Innsbruck Medical University

Division of Physiology

Fritz-Pregl-Strasse 3

6020 Innsbruck

Austria

http://physiologie.i-med.ac.at

e-mail: gerhard.gstraunthaler@i-med.ac.at 